almost certainly mean a rapid rise in populations, with consequential damage to adjoining crops. The pine, and especially the larger blown pine, should thus be salvaged first.

\section{Problems of Salvage}

The timber blown would have had a value standing of more than $£ 4,000,000$. It is essential, therefore, that it should be salvaged before deterioration, alike in the national interest and that of the owners. As already stated, 90 per cent is privately owned, and if a substantial part of its standing value does not accrue to its owners, private forestry and the rehabilitation of private woodlands after the heavy war fellings will be prejudiced seriously in this region.

Largely through the enterprise of the public press, the importance of the problem of salvage is realized widely, and Ministers of the Crown in Parliament and elsewhere have given assurance of help. As soon as the first surveys were completed, the Chairman of the Forestry Commission, accompanied by the Director-General, went to Aberdeen and met the Forestry Commission Regional Advisory Committees for the East and North Conservancies of Scotland, consisting of representatives of private owners, timber merchants and others. The Conservator of the East Conservancy, Forestry Commission, has been put in general charge of the salvage operations, assisted by a small committee of representatives of the regional advisory committees, landowners' organizations and timber trade associations. It has been decided to aim at the completion of salvage within two years. Representatives of the home timber trade in Scotland estimate that there is sufficient sawmill capacity to enable this to be done. The necessary additional logging equipment can be got. Labour is likely to be the limiting factor, and plans are being worked out to obtain what is needed. The Forestry Commission has suspended the licensing of standing softwood timber for clear felling in Scotland, so that the resoturces of the timber trade can be concentrated on the blown timber.

Of the estimated 35 million cubic feet of timber blown, sbout 30 million is softwood from coniferous species, and $\mathbf{5}$ million of hardwoods from broadleaved species. Of the softwoods, it is estimated that about 12 million will go into pitwood and the balance into sawn goods. The hardwood will produce sawn timber. The National Coal Board should be able to absorb the pitwood. The quantity of sawn softwood, although large, is less than 10 per cent of the annual consumption of this category in the United Kingdom ; hence its absorption should not present serious difficulties, although unusually large quantities have been purchased overseas for delivery in 1953. The hardwoods consist principally of beech, and of a quality not suitable for high-grade use, but which could be sawn into railway sleepers and crossings. If the British railways revert temporarily to wartime practice and take this species for this purpose, it would be of assistance. The timber will have to be transported longer distances than normal, both for conversion, and later to consumers. Thus the question of railway-rates will be important in determining the prices obtained by owners of timber.

There are difficult problems still to be solved before the rapid and economic salvage of the blown. timber is ensured, but none is insoluble. They must be solved if the effects of this disaster to forestry in the northern half of Scotland are to bo mitigated by efficient salvage.

\title{
ROLE OF VITAMINS IN METABOLIC PROCESSES
}

$\mathrm{T}$

HE Nutrition Society held a symposium on The Role of Vitamins in Metabolic Processes" in the Biochemistry Department of the University of Sheffield on December 20, 1952. The conference was attended by more than a hundred and thirty members and guests, a number of whom took part in the discussions that followed the reading of the papers. The latter have been published in full in the Proceedings of the Nutrition Society.

In opening the meeting, Prof. H. A. Krebs (Biochemistry Department, Sheffield) said that the subjects of the papers had been chosen with the idea of concentrating attention on the recent advances in this field, and for this reason consideration of thiamine, riboflavin and nicotinamide had been excluded. During the first session, papers were read dealing with pantothenic acid, pyridoxin and vitamin $B_{12}$, substances which are growth factors for micro-organisms as well as for higher animals and which have been shown to have direct connexions with certain metabolic reactions. During the second session, the fat-soluble vitamins and vitamin $\mathrm{C}$ were considered; despite the existence of a considerable body of knowledge relating to the effects of their deficiency, comparatively little is known of the nature of their direct participation in metabolic processes.

Mr. D. E. Hughes (Medical Research Council Unit for Research in Cell Metabolism, Sheffield) showed how the bound forms of pantothenic acid, discovered through the use of micro-organisms for the assay of the vitamin, can now be seen to be various stages in the synthesis or breakdown of coenzyme A. The provisional structure assigned to this coenzyme incorporates a phosphorylated adenosine pyrophosphate and pantetheine, which is a peptide-like compound formed from pantothenic acid and mercaptoethylamine. The thiol group of the latter acts as a carrier of acyl groups in a variety of metabolic reactions. The oxidation of pyruvic acid, for example, results in the formation of acetyl coenzyme A, which may then react with oxaloacetate to give citric acid, thus furthering the oxidative metabolism of carbohydrate, or may contribute to the synthesis of a fatty-acid molecule. Succinyl coenzyme A, and probably other acylated forms of the coenzyme, may arise from other oxidative reactions and may serve in other synthetic reactions-for example, the synthesis of porphyrins.

The signs of pantothenic deficiency in the rat include striking changes in the adrenal cortex. Existing evidence might suggest that these arise, first, through an increased demand placed upon this part of the gland and, secondly, from a lack of ability to perform the synthesis of steroids as a consequence of a lack of coenzyme A. Many tissues, including the adrenal cortex, become depleted of coenzyme $A$ when the diet is deficient in pantothenic acid, and the liver, which is the last to suffer depletion, shows a reduced capacity to acetylate sulphonamides. The greying of the fur and the secretion of porphyrin by the lachrymal glands may be secondary effects of the disturbance of adrenal functions.

Dr. H. M. Sinclair (Laboratory of Human Nutrition, Oxford) reviewed the characteristic signs of deficiency of pyridoxin in the rat, and in other animals. These include changes in the skin (erythema and œdema with superficial hyperkeratosis and 
atrophy of the transitional layers), a microcytic anæmia, and a characteristic gait with, occasionally, epileptiform fits, suggesting changes in the central nervous system. Increased vascularization of the skin in rats is not accompanied by vascularization of the cornea.

As with pantothenic acid, these signs of deficiency bear no simple relation to the known functions of the vitamin as a coenzyme. In the form of pyridoxal phosphate it is apparently concerned with the general metabolism of the amino-acids, as the coenzyme of transamination reactions. It is also required by bacteria for the breakdown of serine and cysteine, and the decarboxylation of certain other aminoacids; and for the synthesis of tryptophane by Neurospora. No satisfactory connexion can be established between the effects of deficiency of the vitamin and a lowered histaminase activity, as was suspected at one time.

Consideration of the possible connexions between these coenzyme functions and the changes in various tissues of the rat can go no further than speculation that protein synthesis is impaired, and that lesions appear where the tissues are most subjected to trauma and thus most need repair. This general connexion between the vitamin and protein metabolism is supported by observations on certain aspects of the protein metabolism of deficient animals.

Dr. J. W. G. Porter (National Institute for Research in Dairying, Reading) reviewed the many results suggesting that vitamin $\mathrm{B}_{12}$, like folic acid, is concerned with the metabolism of one-carbon fragments, such as formyl and methyl groups, in animals and bacteria. In this case, however, the evidence does not extend to the identification of the vitamin as the coenzyme for a specific reaction. Methionine can partly replace vitamin $B_{12}$ in the nutritional requirements of rats and chicks, and can wholly replace it for certain mutants of $E$. coli. Thymidine has been reported to produce hæmatopoietic responses in man and the pig, and it can replace vitamin $B_{12}$ for the growth of Lactobacillus leichmannii. In both cases the explanation could be that the vitamin is required for the methylation of the normal precursors of these substances. These observations connect vitamin $B_{12}$ with protein and nucleic acid synthesis.

A possible clue to the form in which it functions lies in the presence in frees of several forms of the vitamin, having different activities when tested on various organisms. At least five such forms are now known : of these, all are active towards $E$. coli, but two have little or no activity for $L b$. leichmannii. All these forms have been found in small amounts in ox liver.

The presence of cobalt in the vitamin has provoked an investigation of its relation to cobalt deficiency in ruminants, and the most recent results indicate that doses of vitamin $B_{12}$ large in relation to those used to treat pernicious anæmia will cure the symptoms of cobalt deficiency in sheep.

Prof. C. P. H. Dam (Afdeling for Biokemi og Ernaering, Danmarks 'Teknisko Højskole, Copenhagen) was prevented from attending by illness, but his paper, entitled "Recent Studies on Vitamin K", was read for him. $\mathrm{H}_{\theta}$ outlined the relationship between vitamin $K$ and blood coagulation, pointing out its complexity. The fact that the plasma from chicks treated with dicoumarol, or with coumachlor (a rodenticide : 3 -( $\alpha$-phenyl- $\beta$-acetylethyl)-4-hydroxycoumarin), shortens the prothrombin time of plasma from chicks deficient in vitamin $K$, and vice versa, shows that more than one coagulation factor is lacking in vitamin $\mathrm{K}$ deficiency; but mixing the two plasmas does not bring the prothrombin time to its normal value. There are differences between natural vitamin $\mathrm{K}$ and synthetic substitutes for it, sucn as menaphthone (2-methyl-1,4-naphthoquinone); the latter do not counteract the effects of administration of dicoumarol, and the natural vitamin gives a faster reduction of prothrombin time in chicks deficient in vitamin $K$. Prof. Dam thought it more likely that dicoumarol displaces vitamin $K$ from an enzyme system than that it inhibits the synthesis of the vitamin. About 10 per cent of a dose of dicoumarol labelled with radioactive carbon was found in the liver after twenty-four hours. Simultaneous administration of a vitamin $K$ substitute increased the rate of disappearance of the dicoumarol from the liver; the longer the dicoumarol was present in the liver the greater its effect on the prothrombin time.

There are natural variations in the clotting time of blood. A very extensive survey in Copenhagen has shown that for three days after birth there is a rise in the prothrombin time, which may be prevented by the administration of vitamin $K$ to the mother ante partum, or to the infants. Irrespective of treatment, the (lower) adult level is not reached for six months. That hæmorrhages in the new-born cannot be entirely due to the increased prothrombin-time is indicated by the observation that there is a seasonal variation in the frequency of hæmorrhages, but not in the prothrombin time. Prof. Dam compared the observed decrease in mortality attributable to vitamin $\mathrm{K}$ therapy in Copenhagen, one per thousand births, with the extremes of optimism and pessimism attending its first discovery.

In reviewing the other fat-soluble vitamins, Dr. T. Moore (Dunn Nutritional Laboratory, Cambridge) began by pointing out certain differences between vitamins $\mathrm{A}, \mathrm{D}$ and $\mathrm{E}$. The daily doses for rats are, respectively, $0.025,0.5$ and $50 \mu \mathrm{gm}$.; and whereas the precursor of vitamin $A, \beta$-caroten $\theta$, is readily converted to the vitamin in the body, the immediate precursor of vitamin $D$ is formed in the body but cannot be converted to the active form without the aid of ultra-violet light. Vitamin $\mathrm{A}$ has a well-defined role in the cyclic formation of rhodopsin in the eye, and in some organisms this may be its sole function. However, in mammals only a minute fraction of the total vitamin $A$ is present in the retina, and in deficiency of the vitamin characteristic changes are seen in the epithelial tissues, possibly due to the replacement of mucoproteins by keratin. In the vaginal epithelium the effects of cestrogens and vitamin A oppose one another, and excess of either may counteract the normal effects of the other. The metabolic reactions underlying these effects are unknown.

No detailed understanding of tho action of vitamin $\mathrm{D}$ in promoting calcification exists ; but some attempts have been made to substantiate the hypothesis that it acts directly on the conversion of phosphate from the organic to the inorganic form.

The observation that methylene blue can cure or prevent some of the symptoms of vitamin $\mathrm{E}$ deficiency, in particular the pigmentation of the uterus, suggests that vitamin E may have two functions in metabolism : one to serve as an intracellular antioxidant, the other a more specific one connected with reproduction. In vitamin $\mathrm{E}$ deficiency there are chemical changes in the muscles, including the depletion of creatine, and there is evidence of inter- 
ference with protein metabolism. The red blood cells of rats deficient in vitamin $E$ are hæmolysed by dialuric acid.

In the final paper, Dr. L. J. Harris (Dunn Nutritional Laboratory, Cambridge) examined the literature which, despite its bulk, still leaves us without evidence for a specific metabolic role of vitamin C. Among the older hypotheses was one associating ascorbic acid with collagen formation, and also the more general theory that certain formative cells, such as osteoblasts, show reduced activity; in these cells the vitamin has been found to be concentrated in the Golgi apparatus.

Recent studies have established that the metabolism of tyrosine is affected. The intact scorbutic animal (including man) fails to oxidize completely additional tyrosine fed to it, and tissue slices from deficient animals oxidize tyrosine less rapidly than normal.

The extent of conversion of folic acid into folinic acid is reduced in deficiency of the vitamin, a finding which might explain a suspected connexion between scurvy and anæmia.

The adrenal gland, the original source of SzentGyorgyi's 'hexuronic acid', contains high concentrations of the vitamin, and investigations are in progress to see whether any specific relation exists between the activity of the adrenal cortex and the function of the vitamin.

The great majority of animals can synthesize vitamin C, but, although glucose is known to be its precursor, it is still not known whether synthesis is a property of all cells of the body, or whether certain tissues are specialized for this purpose; similarly, the function of the vitamin in plants is still obscure.

J. S. D. BACON

\section{ROYAL SOCIETY MOND LABORATORY, CAMBRIDGE}

\section{By D. D. SHOENBERG}

$\mathrm{T}$ HE Royal Society Mond Laboratory was formally opened on February 3, 1933, by Mr. Stanley Baldwin, then Chancellor of the University. The twentieth anniversary of this occasion was recently celebrated by a party, preceded by demonstrations of phenomena at very low temperatures. In this brief review of the work of the Laboratory, it is appropriate first to recall how much it owes to the initiative and enthusiasm of Dr. P. Kapitza, who was its first director. Soon after Kapitza came to Cambridge in 1921, he became interested in measuring the curvature of $\alpha$-ray tracks by magnetic fields, and this led him to think of the possibility of using magnetic fields much larger than those usually available in electromagnets but lasting for only a small fraction of a second. By limiting the duration of flow of a current in a coil to 1/100 sec., much higher currents can be used without producing too much heat, while at the same time $1 / 100$ sec. is usually ample for the full establishment of any magnetic effect to be studied-thus, for example, an $\alpha$-particle spends only about $10^{-9} \mathrm{sec}$. in the apparatus.

Kapitza first applied this principle in practice by discharging a specially designed accumulator battery through a coil, and breaking the current within a very short time of making by various automatic devices; by this means he studied $\alpha$-ray curvatures, and later the Zeeman effect. The success of these preliminary experiments, in which fields of order 100,000 gauss were obtained, led him to think of more reliable methods of achieving still greater fields, and eventually he set up a large electric alternator which, during half a cycle of its operation, was connected across a coil to give a field of 300,000 gauss over a volume of several cubic centimetres. The equipment required considerable space, not only because of the large size of the machine and control gear, but also because, in order that the mechanical shock of the discharge should not disturb the delicate recording oscillographs, these had to be placed at a distance of about thirty yards away from the generator-a distance greater than that travelled by the shock wave in $1 / 100$ sec. Space was provided on a site now occupied by the Department of Physical Chemistry, and Kapitza carried out $a$ series of pioneer researches on various magnetic properties of matter-particularly the change of resistance of metals in a magnetic field, and also a study of magnetostriction and susceptibility. Many of the effects studied became much more striking at lower temperatures, and this led Kapitza to construct a hydrogen liquefier and to think of a helium liquefier in order to exploit more fully his high-field technique. It became clear that more laboratory space would be required to house such a complex of magnetic and cryogenic research, and the Royal Society made available funds from a bequest of Ludwig Mond in order to build a new laboratory suitable for the purpose, and at the same time appointed Kapitza to be Messel professor and director of this laboratory.

The special requirements of the Laboratory led to an unorthodox but attractive design of building, the central feature of which is a large hall for the highfield equipment, around which are grouped various smaller rooms for research and for the technical services (liquefiers, workshop and machine room); apart from some office accommodation and a conference room on an upper story at one end, the laboratory is mostly on one floor. The central hall later lost its primary function; but I think everyone who has worked in the Laboratory will agree that it has served a useful secondary function in lessening the isolation of the individual research rooms and providing a spacious atmosphere which is, perhaps, lacking in the more conventional type of laboratory built around narrow corridors.

As soon as the new Royal Society Mond Laboratory had been opened and the various machines installed, Kapitza set to work to build a helium liquefier. In characteristic style he preferred to design an entirely new type of machine rather than copy existing ones, and he was successful in developing a liquefier in which cooling below liquid-nitrogen temperatures was achieved by an expansion engine, and no liquid hydrogen was used (although, of course, liquid hydrogen was available from a separate liquefier if required for investigation at higher temperatures). It is interesting to note that Kapitza's machine was the forerunner of the Collins helium liquefier, which has become commercially available, and has been largely responsible for the enormous development of cryogenic research in the United States in recent years.

Just when it seemed that the Laboratory was ready to carry on full-scale research at low temperatures and high magnetic fields, a serious setback occurred when Kapitza was unable to return to Cambridge 